\title{
Impact of Tablet PCs on Creativity in Engineering Design Education
}

\author{
Kevin Firth and Brian Surgenor \\ Department of Mechanical and Materials Engineering \\ Queen’s University, Kingston, Ontario, K7L 3N6 \\ surgenor@me.queensu.ca
}

\begin{abstract}
This paper presents experience with Tablet PCs from the perspective of students in a capstone design course. The authors coordinate an industry based capstone design course. As part of a pilot study, four teams in the course were provided with Tablet PCs with the requirement that they use their tablets as individual electronic design notebooks to replace their conventional hardcopy design notebooks. Experience to date indicates that this technology can enhance creativity in engineering design education.
\end{abstract}

\section{Introduction}

Tablet PCs look much like regular laptop computers, except their digitized screens can be swiveled around, folded over, and written on with a stylus. Instructors have recognized that this simple write-on feature gives them the opportunity to change the way in which they lecture in a classroom. Instead of writing on a board, they write on a tablet over their PowerPoint slides [1, 2]. This paper presents experience with Tablet PCs from the perspective of student's working in teams in a capstone design course. One of the authors coordinates an industry based capstone design course with 160 students that is organized into 40 teams of 4 students each [3]. A pilot study was conducted with selected students to examine the potential impact of this technology.

\section{Background on the Capstone Course}

The final year capstone design course in the Department of Mechanical and Materials Engineering at Queen's University in Kingston (MECH 460 Team Project - Conceive and Design) aims to prepare students for the transition to the workforce by allowing them to experience 'real' engineering work. Students are expected to apply the skills and knowledge learned in earlier courses to an engineering design problem sponsored by industry. There are three main requirements: 1) to complete a significant engineering design project that addresses the conceive and design elements of the design cycle; 2) to perform the engineering work in a professional manner within the constraints of realistic schedules and budgets; and 3) to work effectively as part of an engineering design team. The elective course, MECH 462 Team Project Implement and Operate enables team projects that started in MECH 460 to continue on to the implement and operate stages of the design cycle. A key deliverable in MECH 462 is a working prototype, physical mock-up or virtual model of the design. MECH 460 is a fall term (September to December) course and is mandatory for all students. MECH 462 is a winter term (January to April) course and is optional. About a third of the class (40 to 50 students) elects to continue with MECH 462.

As part of the assessment scheme, students submit weekly progress memos electronically on the Friday of each week. Students are also responsible for providing copies of the memos to their Faculty Supervisor and Industry Advisor. They are expected to meet weekly with their Faculty Supervisor to review progress and discuss any problems. Normally, each student is required to have a bound Design Notebook that provides a record of their individual notes and calculations, as well as a summary of key points and decisions made during each and every group meeting. This was the component of the course to be replaced by an electronic design notebook or edesign notebook. The basic requirement was to be the same, but at the end of term an electronic document was to be submitted instead of a bound hardcopy. 


\section{The Pilot Study}

In Part 1 of the pilot study, 16 students spread across 12 teams volunteered to work with Tablet PCs with the requirement that they use their tablets as electronic design notebooks to replace their conventional hardcopy design notebooks.

In Part 2 of the study, four teams of four students each were provided with tablets with the requirement that they use the tablets as a shared design notebook, as well as use their wireless capability to communicate ideas and brainstorm during face to face team meetings.

Figure 1 illustrates sample notes from a meeting where the students used OneNote (part of the MS Office suite of software) to work simultaneously on a sketch page. Colour coding was used to track individual contributions.

\section{Impact of the Tablet PC's}

In Part 1 of the pilot study (MECH 460), the tablets were given to individual students to use. In most cases, there was only one tablet per team. An informal participant survey was conducted for Part 1 at the end of the course. The universal observation made by the students was that they considered the tablets to have made a significant positive contribution to their learning experience and strongly recommended that steps be taken to introduce them formally into the design curriculum.

The following specific benefits were observed for those students who were given the opportunity to use the Tablet PC as an electronic design notebook:

- better recording of design discussions, decisions and changes during team meetings

- more engineering analysis as the design evolved during the course of the term

- better recording and sharing of minutes for meetings and communications

Figures 2 to 5 illustrate sample content found in edesign notebooks that were submitted in Part 1 . As was appropriate, the materials covered every aspect of the student's work: preliminary sketches (Figure 2), hand calculations (Figure 3), software based analysis (Figure 4) and parts sourcing from the web (Figure 5). Figure 4 is noteworthy because the typed text that appears in the figure was originally handwritten and the students made use of the "translate" facility that is provided with the notebook to convert the handwriting to formal text.

In Part 2 of the pilot study (MECH 462), the tablets were handed out on a team basis. A formal

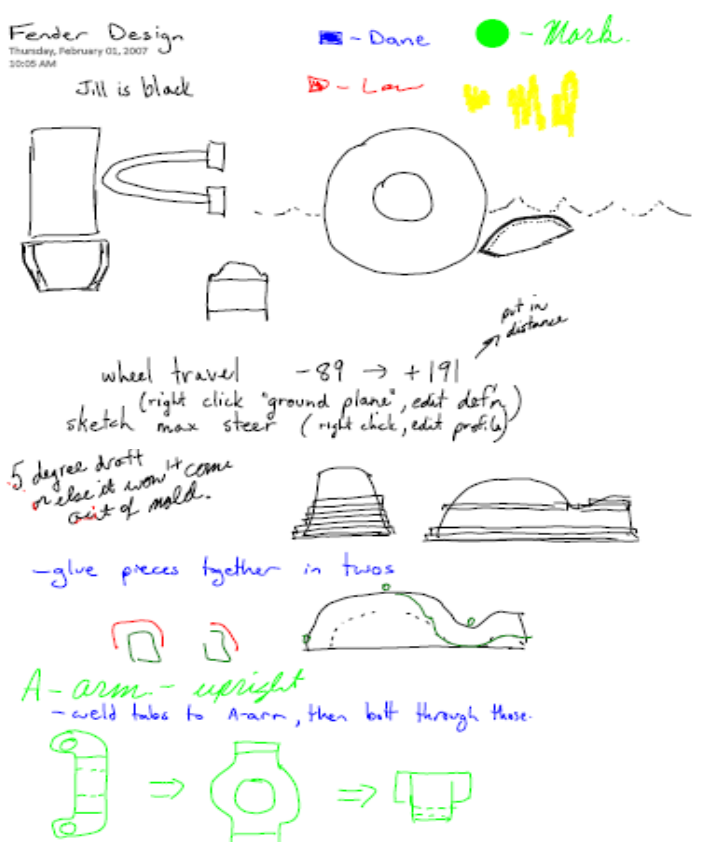

Figure 1. Example of a shared sketch page

participant survey was conducted for Part 2 at the end of the course in which the students were asked to reflect on their experience in both MECH 460 and MECH 462. The key results are given in Figure 6 and can be summarized as follows:

1) Majority of students "strongly agreed" that the Tablet PC based electronic design notebook is more effective than a hardcopy design notebook

2) All students would be willing to pay a premium for a Tablet PC if they were in the market for a new computer, with the premium ranging from $\$ 125$ to $\$ 500$ (on a $\$ 1,500$ computer)

3) Students were "neutral" on the question of whether a Tablet PC accelerates idea generation and design analysis during team brainstorming

4) It was unanimous that the students "strongly agreed" or "agreed" that a Tablet PC encourages students to sketch, to both capture and share design ideas

5) It was almost unanimous that the students "strongly agreed" or "agreed" that a Tablet PC promotes better record keeping, for the team design notebook 
Key Requirements:

- Need an adjustable track at boat

base

- Need to fix rake angle per sail

(but possibly differ per sail size)

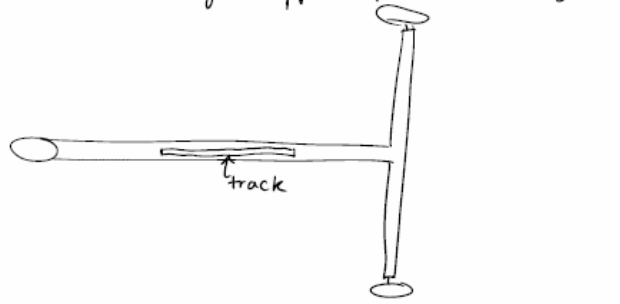

$$
\begin{aligned}
& \begin{array}{l}
\text { screw to tighten in sleeve at set angle? } \\
\text { location mast simply slides in } \\
\text { cards" } \\
\text { \& set screw tightens to } \\
\text { ensure a secure fit }
\end{array} \\
& \text { mast height seems okay at } 1.5 \mathrm{~m} \\
& \text { But It should be a single piece design }
\end{aligned}
$$

Figure 2. Written notes from an e-design notebook

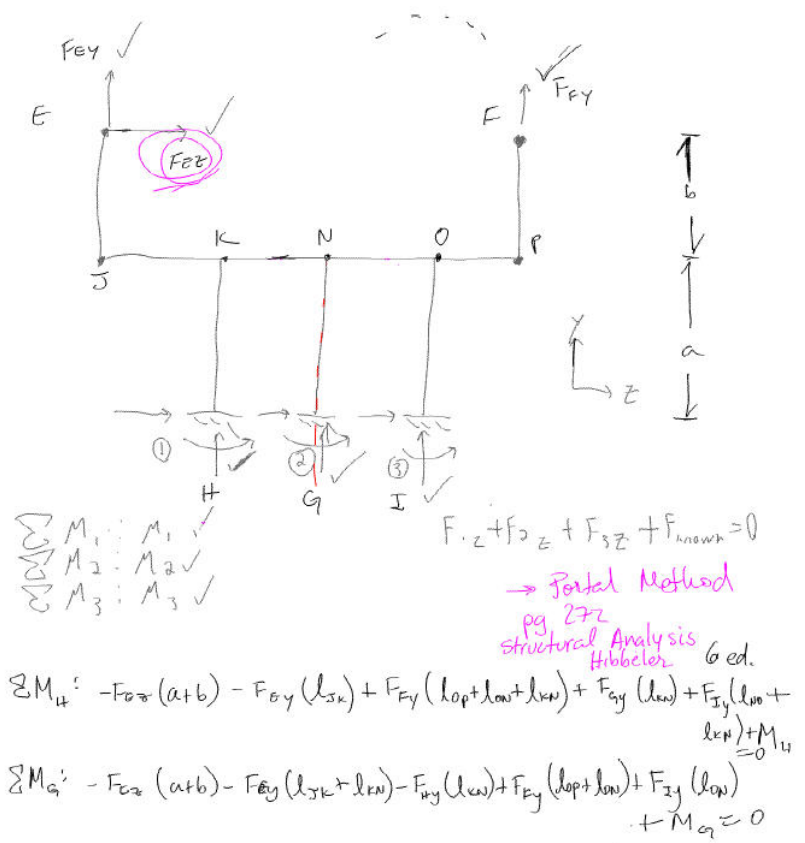

Figure 3. Calculations with notes by another student

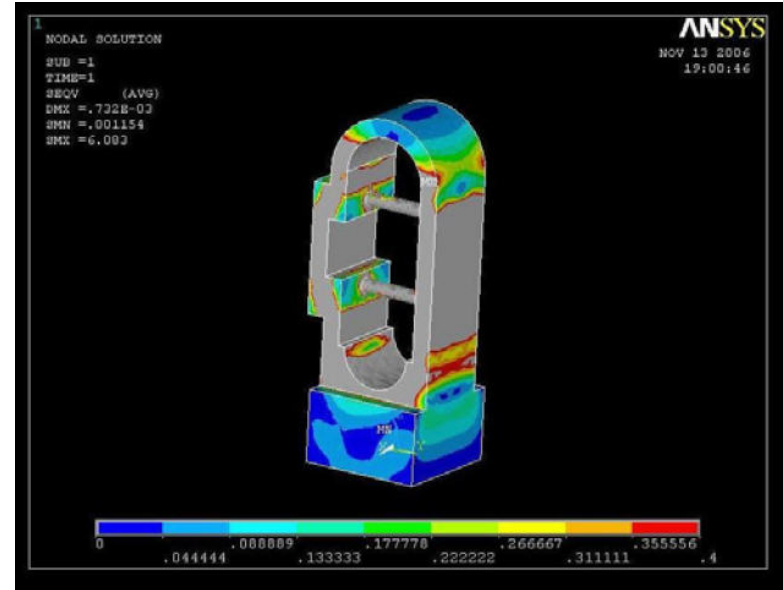

Tuesday, November 14, 2006

Meeting with Slav (4:30-5:30pm)

- Showed Slav simulation results from ANSYS

- Suggested to simulate or hand calculate cycle time before failure - Use Stromberg

- Realized simulation was performed inaccurately

- Half load on Front Mount

Q Quarter load on each of the Rear Mounts

- Improper part dimensions

Figure 4. Sample FEA result with "translated" notes from an e-design notebook

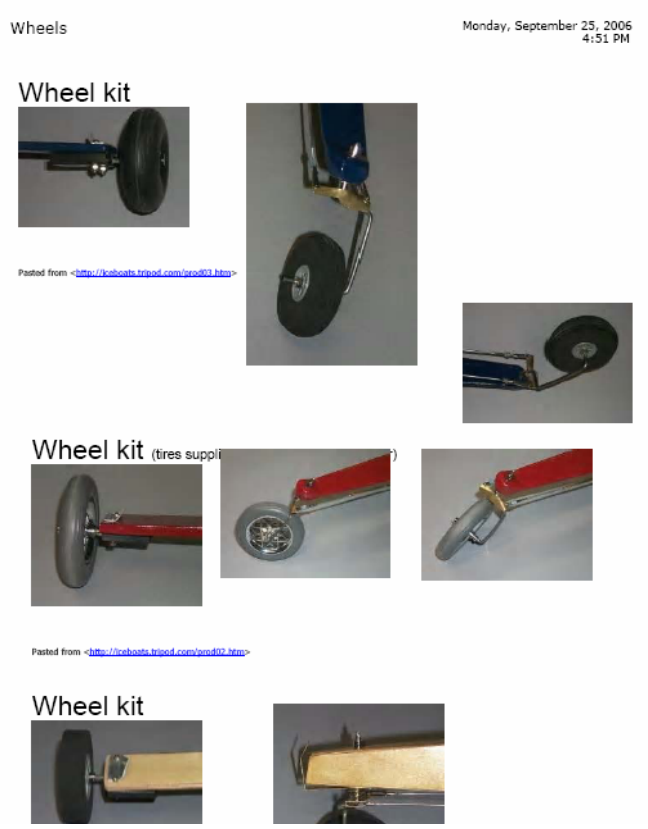

Figure 5. Web extract from an e-design notebook 
Overall, a tablet PC based $\mathbf{4 6 0}$ design notebook is more effective than a hardcopy design notebook.

1. Strongly Agree

2. Agree

3. Neutral

4. Disagree

5. Strongly Disagree

Question 1

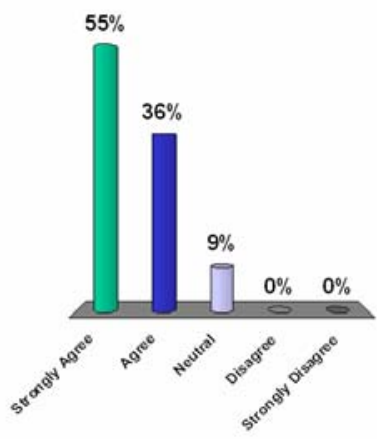

A tablet PC accelerates idea generation and design analysis during team brainstorming.

1. Strongly Agree

2. Agree

3. Neutral

4. Disagree

5. Strongly Disagree

Question 3

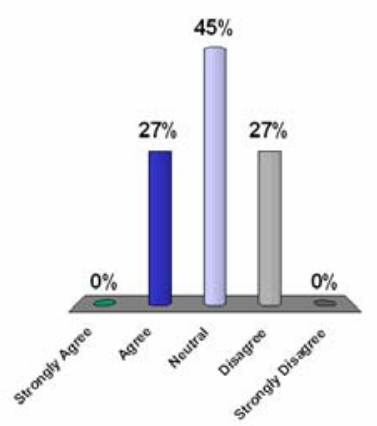
(for the end of term team design notebook).

1. Strongly Agree

2. Agree

3. Neutral

4. Disagree

5. Strongly Disagree

Question 5

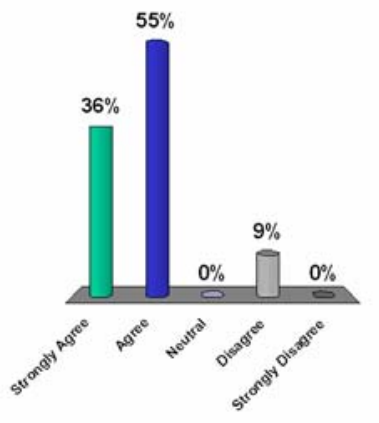

How much of a premium would you pay for a tablet PC ? (assuming base price of $\$ 1,500$ )

1. $\$ 500$

2. $\$ 375$

3. $\$ 250$

4. $\$ 125$

5. $\$ 0$

Question 2

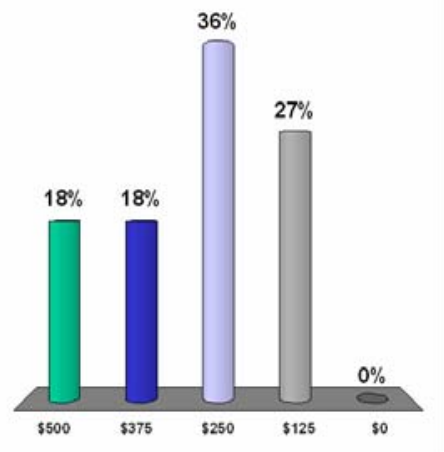

A tablet PC encourages students to sketch, to both capture and share design ideas.

1. Strongly Agree

2. Agree

3. Neutral

4. Disagree

5. Strongly Disagree

Question 4

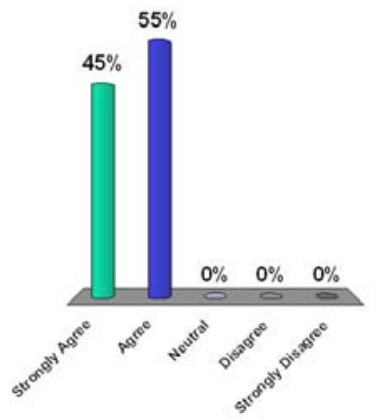

Next year in 460 , give one tablet to 20 teams (instead of 4 tablets per team for 5 teams).

1. Strongly Agree

$45 \%$

2. Agree

3. Neutral

4. Disagree

5. Strongly Disagree

Question 6

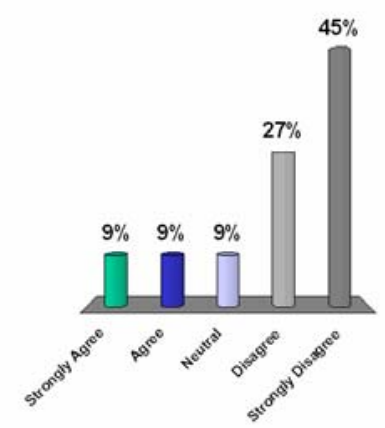

Figure 6. Student survey results from Part 2 of pilot study 
In the sixth question, the students were asked to comment on the manner in which the tablets should be used during the next offering of the courses. The students supported the scenario where the tablets were assigned on a team basis (every member with a tablet). They felt that handing out the tablets on an individual basis would significantly degrade their effectiveness.

The experience at Queen's appears to parallel the experience at MIT [4] where tablets were given to selected students in a senior year design course. The conclusions at MIT as they relate to the Queen's experience were:

- tablets were most useful for the early phases of design, and less useful during the build phase

- during the build phase, the convenient size of machines and wireless internet access was very useful as students could quickly access manufacturing tips from the web and could easily update their solid models (in the machine shop) as during manufacture

The teaching staff at MIT reported that there was no noticeable difference in performance between tabletbased students and non-tablet-based students. However, the tablet-based students were more likely to create and refine their analysis using software tools as opposed to just noting the analysis in their design notebooks.

\section{Thoughts on Creativity}

It is a given that new technology such as Tablet PCs excites engineering students. But one of the underlying questions for this study is whether or not new technology also promotes creativity? Research clearly shows that it is possible to enhance creativity though various types of classroom-based exercises and instruction [5]. Unfortunately, due to limited resources and time, students rarely get exposed to these creativity building exercises. There is an inherent advantage to any exercise that simply involves handing the students a new "creativity toy", which they will use on their on time using their own initiative.

In Richards' study on ways to stimulate creativity" [6], he provided a list of strategies and techniques for enhancing personal creativity:

1) Immerse yourself in a domain or problem

2) Be prolific, generate lots of ideas

3) Use tools for representation and thought

4) Play with ideas, think from abstract to concrete
5) Avoid premature closure, don't stop with the first idea

6) Don't be afraid to be different, be independent

7) Be open and receptive to new ideas

8) Do it, practice your craft, design things

9) Maintain a product orientation, finish your projects

10) Relax, take your time, indulge in diversions

11) Reflect, review what you have done

12) Have fun

Point 3) is directly relevant to this study as it addresses the need for students to keep a notebook. "Don't rely on memory. You might lose your best ideas. Write things down, sketch, draw and diagram, model using computers, construct physical prototypes.” [6]

Richards confirms that an essential component of any design course is keeping individual and team notebooks: detailed accounts of the activities, processes, products, reflections and reactions to the projects at hand. He points out that these records are critical when it comes to the thinking and reflection phase of the design process. Students (and professors) are notorious for keeping poor records, or at the very least, keeping records that only the original author can decipher. Thus, the fact that the Tablet PC appears to enhance recording keeping (both textual and drawing formats), leads one to the conclusion that it also serves to promote creativity.

There is another way of looking the issue of creativity. Comparing the electronic notebooks with the conventional paper-based notebooks indicates that the stylus interface of the Tablet PC does bring drawing into the laptop environment. Students sketch on blank space, trace and augment graphics captured from the Internet and annotate lecture notes with sketches as well as text. While it is difficult to determine the contribution this makes to the creative component, observing students using their tablets individually and in teams one sees the frequent use of drawing as a tool for thinking and communicating. Looking forward, there may be an opportunity with this technology to encourage students to enhance their sketching and 3-D visualization skills in all years of their engineering program.

It is interesting to consider these observations in the context of the preface made by Edwards in her book on teaching the basics of how to draw:

“... drawing is a teachable, learnable skill that can provide a twofold advantage. (first) By gaining access to the part of your mind that works in a style conducive to creative, intuitive 
thought, you will learn a fundamental skill of the visual arts: how to put on paper what you see in front of your eyes. Second, through learning to draw (by the method presented in this book), you will enhance your ability to think more creatively in other areas of your life". [7]

In the context of design, we may want to extend the view "in front of your eyes" to include "in front of your mind's eye".

\section{Conclusions}

This paper examined the impact of Tablet PCs when applied to a final year capstone design course. In the first term, the Tablet PCs were used to replace the traditional individual design notebook. In the second term, the wireless capability of the Tablet PCs was used to enable a shared design notebook as well as to provide for "electronic brainstorming" during team meetings.

In summarizing the Queen's experience, it was found that the students used this opportunity to fully explore the potential of the new technology. Although the students felt that the tablet interface did not necessarily improve the speed of idea generation and design modifications, they did acknowledge that brainstorming sessions took place with much more energy. The tablets did enable teams to think together more effectively in the language of sketching. It is believed that this technology can be used to significantly enhance the design experience throughout the curriculum. Consequently, the positive experience in this pilot study is being used to encourage the application of Tablet PC technology to other design courses.

\section{Acknowledgments}

This work was supported by an HP Technology for Teaching Higher Education Grant.

\section{References}

[1] Wu, C. “Take a Tablet” ASEE Prism, Vol. 16, No. 4, pp. 42-45, 2006.

[2] Anderson, R., VanDeGrift, T., Wolfman, S., Yasuhara, K. and Anderson, R.E. "Experiences with a Tablet PCBased Lecture Presentation Systems”, SIGCSE (Assoc. for Computing Machinery), Norfolk, Mar. 3 to 7, 2004

[3] Mechefske, C.K., Surgenor, B.W. and Wyss, U.P. "Design Projects: CDIO Context and Experience with Industry", $2^{\text {nd }}$ CDEN Int. Conf. Design Education, Innovation and Practice, Kananaskis, Alberta, July 18 to 20, 2005.

[4] Slocum, A.H. and Willoughby, P.J. "The MIT iCampus RobotWorld Project - The Peer Review Process and Tablet PC Experiences”, $1^{\text {st }}$ Ann. CDIO Conf., Kingston, Ontario, July 7 to 8, 2005.

[5] Raviv, D., Morris, M., Ginsberg, K. ”On Teaching and Assessing Engineering Innovation”, ASEE Conference, 2005, Portland, June 12 to 15, 2005.

[6] Richards, L.G. "Stimulating Creativity: Teaching Engineers to be Innovators", Frontiers in Education (FIE) Conference, Tempe, Arizona, Nov 4 to 7, 1998.

[7] Edwards, B. "Drawing on the Right Side of the Brain”, New York, Tarcher Putnam, 1999. 